\title{
ARTES VISUAIS E EAD: UM APRENDIZADO POSSÍVEL?
}

\author{
ANDRY MÁrCIA LOPES \\ Instituto Federal de Educação, Ciência e Tecnologia do Norte de \\ Minas Gerais (IFNMG), Montes Claros, Minas Gerais, Brasil \\ Fábia Magali Santos VieIRa \\ Universidade Estadual de Montes Claros (Unimontes), Montes \\ Claros, Minas Gerais, Brasil
}

Resumo: Este trabalho tem como objetivo apresentar os dados de uma pesquisa desenvolvida durante o curso de especialização lato sensu em Didática e Metodologia do Ensino Superior na Universidade Estadual de Montes Claros (Unimontes); assim como compreender o processo de ensino-aprendizagem da disciplina Desenho em um curso de graduação em Artes Visuais a distância, identificando as dificuldades encontradas pelo docente e pelos discentes, bem como as estratégias didáticas utilizadas. As informações foram levantadas por meio de entrevistas e de pesquisa documental com portfólios de Desenho e análise das salas virtuais. Ao fim da pesquisa concluiu-se que é possível aprender o desenho em um curso a distância se houver na instituição uma estrutura que atenda às necessidades desta disciplina.

Palavras-chave: Educação a Distância. Artes Visuais. Ensino-aprendizagem. Desenho.

INTRODUÇão

Esta pesquisa teve como campo de estudos os limites e as possibilidades da disciplina Desenho no curso de graduação em Artes Visuais a distância. 
Considerando que o contato com o desenho é importante na formação de arte-educadores visuais, a investigação teve como objetivo compreender como o processo de ensino-aprendizagem da disciplina Desenho acontece na graduação do curso de Artes Visuais ministrado pelo Sistema Universidade Aberta do Brasil (UAB). Buscou-se identificar e analisar as dificuldades encontradas pelos alunos e também as estratégias didáticas e recursos tecnológicos desenvolvidos e utilizados pelos professores durante o trabalho com a referida disciplina.

Entender os limites da educação a distância foi uma inquietação que surgiu desde a formação na licenciatura em Artes/ênfase em Artes Plásticas de uma das pesquisadoras, pois, graduada em um curso presencial, não estava claro para a mesma as possibilidades sobre ensinar e aprender as disciplinas práticas em cursos a distância. Ter a oportunidade de trabalhar na tutoria da UAB/Unimontes possibilitou a pesquisadora em questão sanar muitas dúvidas e ao mesmo tempo aguçou o interesse de aprofundamento sobre o tema.

Assim, o problema desta pesquisa partiu da seguinte questão: é possível aprender a desenhar em um curso de licenciatura em Artes Visuais a distância? Quais os fatores que contribuem ou dificultam o processo ensino-aprendizagem dessa disciplina em um curso de graduação a distância?

Salientamos que a disciplina pesquisada trata-se do desenho de observação, inicialmente observações realizadas com base em composições da natureza morta, posteriormente a observação da figura humana em fotografias, finalizando com trabalhos de observação de modelo vivo.

\section{APORTES METODOLÓGICOS}

Quanto aos objetivos esta pesquisa foi classificada como explicativa, pois teve a pretensão em identificar os fatores que determinam ou que contribuem para que se ocorra um fenômeno. Quanto aos procedimentos técnicos utilizados, pode ser classificada em estudo de caso que, conforme Gil (2002), trata-se de um estudo aprofundado de um ou de poucos objetos, permitindo seu detalhado e amplo conhecimento.

Para a coleta de dados, foram realizadas observações, entrevistas e pesquisa documental. As observações foram realizadas nas salas de Desenho 
do Ambiente Virtual de Aprendizagem (AVA) - denominado Virtualmontes. Foram entrevistados seis dos 28 alunos matriculados no polo de apoio presencial do município de Buritizeiro (Minas Gerais), sendo três alunos que se encontravam entre os alunos com maiores notas nas disciplinas de Desenho, que denominaremos Aluno I, Aluno II e Aluno III; e três alunos que se encontravam com menores notas em Desenho, que denominaremos Aluno IV, Aluno V e Aluno VI. Também foi entrevistada a professora formadora da disciplina Desenho III e Desenho IV, que será denominada professora "B".

A pesquisa documental foi realizada com análise do Projeto Político pedagógico do curso de Artes Visuais UAB/Unimontes e dos portfólios de Desenho dos acadêmicos. Os dados coletados nas observações, entrevistas e pesquisa documental foram analisados segundo uma abordagem qualitativa.

\section{A Disciplina Desenho no Curso de Artes Visuais a Distância: Pressupostos Té́ricos e MetodolóGicos}

As diferentes concepções de educação a distância

Atualmente, por atender às transformações sociais e econômicas contemporâneas, a educação na modalidade a distância é um processo de ensino-aprendizagem que se encontra em constante crescimento. Consequentemente são muitos os estudos acerca do tema em questão."Porém uma enorme confusão tem sido feita em torno do que se entende por ensino a distância, educação a distância e educação aberta e a distância" (VIEIRA, 2003, p.32). É relevante perceber a distinção entre os três termos, visto que se trata de concepções diferentes de educação. Para Vieira (2003), esses termos estão relacionados às concepções de educação Positivista, Idealista e Dialética. Para tanto, é importante distinguir o que é ensinar e aprender e o que é educar em cada uma das concepções de educação para definir o que se entende por educação a distância.

Schaff (1987) define o processo do conhecimento como uma interação específica entre a tríade sujeito, objeto e conhecimento: o sujeito que conhece, o objeto a ser conhecido, sendo os processos mentais o resultado dessa interação - o conhecimento. A partir dessa definição, Schaff (1987) 
propõe três teorias para explicar a origem do conhecimento voltado para modelos cientificamente teóricos: mecanicista ou teoria do reflexo; idealista e ativista; e o modelo objetivo-ativista.

O modelo mecanicista ou teoria do reflexo possui esta denominação devido ao conhecimento ocorrer como resultado de um reflexo da ação mecânica do objeto sobre o sujeito. Para Schaff (1987) neste modelo, o sujeito, na relação cognitiva, tem o papel de registrar e refletir os estímulos vindos do exterior e, portanto, a ênfase está no objeto que atua sobre o sujeito receptivo. No segundo modelo, idealista e ativista, a ênfase está no sujeito que conhece, "o objeto do conhecimento desaparece, e a função do sujeito ganha maior importância, atribuindo-lhe papel ativo e idealista" (VIEIRA, 2003, p.27). O objeto do conhecimento é produção do sujeito, sendo este exclusivo no processo e criador da sua realidade. Se no primeiro modelo a ação é no objeto, e no segundo modelo no sujeito, no terceiro modelo - o objetivo-ativista - sujeito e objeto ganham fundamental importância na produção do conhecimento. A relação cognitiva entre o sujeito que conhece com o objeto a ser conhecido ocorre de maneira que um atua sobre o outro.

A partir dos modelos de origem do conhecimento propostos por Schaff (1987) estabeleceremos uma relação entre as teorias de aprendizagem às três principais concepções de educação e as concepções de educação a distância conforme quadro a seguir proposto por Dias (2004):

Quadro 1: Pressupostos dos modelos de educação a distância

\begin{tabular}{|c|c|c|c|}
\hline $\begin{array}{l}\text { Origem do } \\
\text { conhecimento }\end{array}$ & $\begin{array}{l}\text { Teoria de } \\
\text { aprendizagem }\end{array}$ & $\begin{array}{l}\text { Concepção de } \\
\text { Educação }\end{array}$ & $\begin{array}{l}\text { Concepção de Educação à } \\
\text { distância }\end{array}$ \\
\hline Teoria do reflexo & Behavorista & Positivista & Ensino a distância \\
\hline Idealista e ativista & $\begin{array}{l}\text { Interacionista } \\
\text { Construtivista }\end{array}$ & Idealista & Educação a Distância \\
\hline Objetivo - ativista & $\begin{array}{l}\text { Interacionista } \\
\text { Sócio - interacionista }\end{array}$ & Dialética & Educação Aberta e a Distância \\
\hline
\end{tabular}

Fonte: DIAS, 2004, p.17

Discutiremos as três concepções de educação a distância a partir das três concepções de educação vistas até aqui: Ensino a Distância (ED), Educação a Distância - EaD, e Educação Aberta e a Distância (EAD). 
Os princípios de Ensino a Distância (ED) são baseados na educação positivista: o aluno tem acesso ao conteúdo por meio de livros e manuais, e recebe o conteúdo transmitido de maneira passiva. A formação do aluno é específica em determinado trabalho em que teoria e prática não se misturam.

Nessa perspectiva, o ensino a distância, como a própria expressão diz, tem o processo centrado no ensino, na transmissão de informações" (VIEIRA, 2003. p. 32).

Os princípios de Educação a Distância (EaD) baseiam-se na concepção idealista. "Nessa perspectiva, a educação a distância se fundamenta no pressuposto do segundo modelo de Schaff, o idealista e ativista e se baseia em pouca ou nenhuma interação entre professores e estudantes" (VIEIRA, 2003 , p. 34). Os recursos utilizados são a televisão e os vídeos, sendo relevante apenas o processo pelo qual se leva o ensino.

A Educação Aberta e a Distância (EAD) baseia-se na concepção de educação dialética, e, portanto, busca a formação do ser autônomo, crítico e capaz de buscar as respostas para os seus questionamentos. "Assim, a Educação Aberta e a Distância - EAD apresenta-se como uma forma de educação que possibilita a democratização do saber independente do tempo e do espaço" (VIEIRA, 2003, p. 34).

A concepção de estratégias adequadas de utilização dos materiais e tecnologias de aprendizagem a distância, que são tão ou mais importantes que os próprios materiais é fundamental para o acesso de uma ação educacional a distância. Estas estratégias devem ser parte integrante dos materiais, tendo como objetivo promover, orientar e facilitar a aprendizagem autônoma. (BELLONI, 2006, p. 103).

Na EAD, o professor assume um papel mediador com a utilização de ferramentas que permitam a comunicação em tempos e espaços diferentes.

\section{O Desenho na FormaÇão do Arte-EDUCAdor}

Durante sua formação docente, o professor deve desenvolver competências que estejam voltadas para a formação pedagógica e a formação específica da sua área de conhecimento. “No caso do professor de Arte, a 
sua prática-teoria artística e estética deve estar conectada a uma concepção de arte, assim como a consistentes propostas pedagógicas. Em síntese, ele precisa saber arte e saber ser professor de arte" (FUSARI; FERRAZ, 1993, p. 49).

Um curso de licenciatura em Artes deve proporcionar aos acadêmicos o desenvolvimento de competências que estruturem as linguagens artísticas que o permitam produzir arte. Nas palavras de Coutinho (2003), um curso que forma professores de Arte deve proporcionar aos seus alunos uma imersão na linguagem artística, para que o mesmo reflita criticamente acerca do conhecimento implicado no processo, pois o aluno, futuro professor de Artes, é estimulado a um contato com sua poética pessoal através de suas produções:

A formação do professor de Arte tem, portanto, este caráter peculiar de lidar com as complexas questões de produção, da apreciação e da reflexão do próprio sujeito, o futuro professor, e das transposições das suas experiências da Arte para a sala de aula com seus alunos [...]. (COUTINHO, 2003, p. 157).

O domínio do desenho possibilita ao aluno aprofundar-se no universo da arte, inicialmente examinando e desenhando suas observações, ato que o favorece amadurecer e refletir sobre seu olhar observador, e sequencialmente construir conhecimentos que agucem suas percepções de ser no mundo. $O$ estudo do desenho, portanto, é de fundamental importância para o futuro professor das Artes Visuais, pois é por esse estudo que se desenvolve a observação, abrindo a possibilidade de reflexão sobre a matéria e o espaço, para futuramente aplicar em seu ensino. O desenho de observação pode se tornar um importante aliado da percepção e do pensamento visual interpretante, desde que se valorize a autonomia dos elementos plásticos, como ressalta Silva (2010):

A função do desenho consiste na aquisição de uma literacia visual consistente, na medida em que conduz ao domínio instrumental da representação gráfica, bem como apoia a produção de uma consciência crítica face às imposições da sociedade de consumo. Em síntese, o desenho desenvolve a percepção visual aguda e veicula valores intrínsecos à criatividade e à motivação intrínseca, bem como estimula o sentido crítico, a capacidade de análise e a valorização de tarefas em benefício do prazer pessoal. (SILVA, 2010, p.37)

Como destaca a autora, não se trata apenas de um processo mimético de recriação visual da imagem com base na cópia, mas de um trabalho que 
atenda às novas condições de aprendizagem da arte-educação contemporânea. Com isso, conclui-se a importância em o estudante de Artes Visuais, futuro arte-educador, vivenciar e experimentar o desenho em sua formação acadêmica, praticando-o através da observação e do exercício, pois assim, ao se tornar um educador que trabalha com arte, terá a formação artística atrelada à sua formação de educador.

\section{A formação do professor de Artes Visuais a distância.}

De acordo com a análise do Projeto Político Pedagógico (PPP) de licenciatura em Artes Visuais UAB/Unimontes, o curso foi realizado em oito períodos letivos que acontecerá entre 2008 e 2012. Os estudos da disciplina Desenho aconteceram do $1^{\circ}$ ao $4^{\circ}$ período, sendo as respectivas disciplinas: Desenho I, Desenho II, Desenho III e Desenho IV. A estrutura curricular do curso divide-se em oito módulos, sendo um por semestre, distribuído em quatro anos.

O perfil profissiográfico do curso de licenciatura em Artes Visuais $\mathrm{UAB} /$ Unimontes visa à formação de professores que tenham condições de elaborar conteúdos e práticas de ensino e aprendizagem em Artes Visuais para as modalidades de ensino formal e não-formal, explorando de maneira crítica a produção artística inter-relacionando arte, cultura e educação.

O Curso tem como fundamentos filosóficos e epistemológicos, baseados nas Diretrizes Curriculares nacionais para os cursos de licenciatura e fundamentos legais, conforme constam na LDB n॰ 9394/96 que institui as Diretrizes e Bases da Educação Nacional; Resolução CNE/CP n¹/2002, que institui Diretrizes para a formação de professores da Educação Básica, nível superior, curso de licenciatura, de graduação Plena; na Resolução CNE/CP n 2/2002,a qual institui duração e carga-horária dos cursos de licenciatura; na Resolução CEE/MG n 447/2002 e Portaria no 1065 de 25/05/2006, que credenciam a Universidade Estadual de Montes Claros para a oferta de educação a distância ( UAB/UNIMONTES 2008, p.19-20).

O programa Universidade Aberta do Brasil (UAB) tem como prioridade a capacitação de professores da Educação Básica cujo objetivo é estimular a articulação e a integração de um sistema nacional de educação superior, formado por instituições públicas de ensino superior que se comprometem 
a levar o ensino público de qualidade aos municípios brasileiros. Em abril de 2008, nove cursos de Licenciatura foram selecionados: Artes Visuais, Ciências Biológicas, Ciências Sociais, Geografia, História, Letras Português, Letras Inglês, Letras Espanhol e Pedagogia. São oferecidos em doze polos de apoio presencial, divididos em UAB I, II e III em parceria com o MEC e prefeituras municipais.

As aulas presenciais são realizadas nos polos onde estão montados os laboratórios de informática e os didáticos. Para o desenvolvimento das atividades presenciais das aulas de Desenho, o PPP salienta a importância de um atelier de desenho e pintura, onde poderão ser realizadas as atividades práticas relativas a diferentes períodos e disciplinas. $\mathrm{O}$ espaço deverá ser composto, basicamente, por duas salas equipadas com uma pia, 25 mesas e 25 cadeiras, numa área total de aproximadamente $60 \mathrm{~m}^{2}$.

Composta pelo coordenador e coordenador adjunto, responsáveis pela articulação e operacionalização dos cursos/polos; a Coordenação didática, composta pelo coordenador de curso indicado pelo colegiado didático e a Coordenação pedagógica, composta pelos professores e tutores (quadro 2)

Quadro 2: Organograma do sistema de tutoria para atendimento aos acadêmicos

\begin{tabular}{lll}
\hline Função & Especificações & Horas Semanais dedicadas \\
\hline Professor & 01 professor para cada disciplina & $20 \mathrm{~h}$ \\
\hline Tutores presenciais & 01 tutor por curso, no polo. & $20 \mathrm{~h}$ \\
\hline Tutores a distância & 01 tutor para cada grupo de 25 acadêmicos. & $20 \mathrm{~h}$ \\
\hline
\end{tabular}

Fonte: UAB/UNIMONTES, 2008, p.32

No que compete às atribuições e/ou funções do professor formador, de acordo com o Projeto Político Pedagógico do curso Pedagogia da UAB, verificou-se que

O professor formador é responsável pelo planejamento, realização e avaliação da disciplina sob sua responsabilidade, com as seguintes contribuições:

- ministrar e avaliar a disciplina;

- planejar os seminários introdutórios e seminários temáticos;

- orientar os tutores a distância e presenciais;

- planejar e orientar as atividades para recuperação da aprendizagem; 
- coordenar diretamente as Avaliações Presenciais Semestrais (AS) e responsabilizar-se pelo registro dos resultados na Secretaria Geral. (UAB/ UNIMONTES, 2008, p.64)

Em relação ao papel dos tutores a distância

Têm a função de dar assistência, aos professores/formadores, orientar os tutores presenciais e os cursistas. Estes profissionais permanecerão na Unimontes e darão suporte remoto (telefone, e-mail) aos tutores presenciais e cursistas. (UAB/UNIMONTES, 2008, p. 65):

Em relação ao papel do tutor presencial podemos citar algumas de suas funções, de acordo com o PPP dos cursos:

Têm a função de acompanhar e orientar os acadêmicos do curso, no pólo de apoio presencial; planejar as atividades para recuperação das atividades; realizar, juntamente com os professores formadores, os seminários introdutórios e seminários temáticos; colaborar com a realização das atividades da Fase Presencial Intensiva; aplicar as avaliações on-line (AO) e as avaliações semestrais (AS); orientar e acompanhar as atividades de estágio, TCC e AACC. (UAB/UNIMONTES, 2008, p. 69).

São as seguintes modalidades de avaliação: Atividades Avaliativas $(\mathrm{AA})$, que são exercícios relacionados às unidades didáticas trabalhadas no módulo; Avaliações a distância mensais (AM) são de caráter formativo aplicadas pelos tutores presenciais e por eles corrigidas, ou podem ser também exames a distância enviados mensalmente pelo tutor presencial ao cursista; Avaliações presenciais semestrais (AS), ou seja, avaliações realizadas nos polos presenciais, que ocorrem no final de cada módulo em dias e horários preestabelecidos, incluídos no calendário escolar que correspondem, no mínimo, a nota de $50 \%$ da nota final do cursista.

\section{A Disciplina Desenho no Curso de Artes Visuais a Distância: Análise e DISCUSSÃO DOS DADOS}

Em relação ao perfil dos acadêmicos pesquisados todos trabalham e, no que se refere à idade, dos seis alunos obteve-se os seguintes dados, disponíveis no gráfico 1: 
Gráfico 1 - Perfil dos acadêmicos pesquisados.

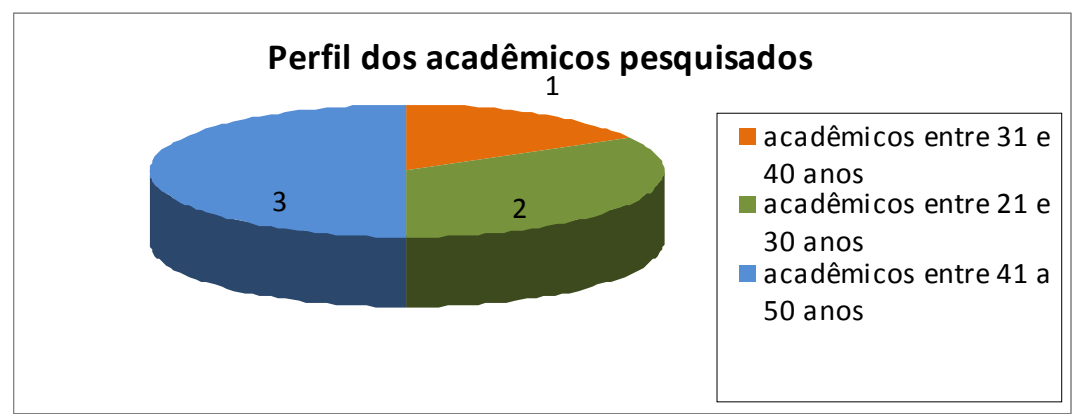

Fonte: elaborado pelas autoras

De acordo Belloni (2006, p. 45), os estudantes a distância são na maioria adultos entre 25 e 40 anos, que trabalham e estudam em tempo parcial. Em relação ao trabalho, a afirmação da autora é confirmada pelos dados dos alunos, sendo que $100 \%$ dos pesquisados trabalham, mas em relação à idade percebe-se que pessoas acima dos 40 anos de idade também têm optado pela educação a distância, visto que $50 \%$ dos entrevistados encontram-se entre 41 e 50 anos.

Sobre o perfil da professora pesquisada obtivemos os seguintes dados: graduada em Artes Visuais pela Escola de Belas Artes da Universidade Federal de Minas Gerais (UFMG), com bacharelado em Desenho em 2001, e complementação em licenciatura em Desenho e Plástica em 2002. A professora especializou-se em Docência do Ensino Superior em 2006. Sua trajetória profissional está toda voltada para o ensino, inicialmente no ensino fundamental e médio, depois no ensino superior. Na Unimontes, a professora pesquisada iniciou sua carreira docente no curso de Artes Visuais/ UAB após ser selecionada para a tutoria e atualmente é professora também do curso de Artes Visuais modalidade presencial. Após a experiência como tutora a distância, a professora pesquisada teve sua primeira experiência como professora formadora em dependência de Desenho I, ministrando depois as disciplinas Desenho III e Desenho IV da UAB/ Unimontes. 


\section{A Percepção dos Acadêmicos}

Durante os estudos através da plataforma Virtualmontes e das aulas presenciais, os acadêmicos realizaram exercícios de desenho e foram orientados a compor um portfólio com os exercícios práticos e também a escreverem no mesmo sobre suas dificuldades, anseios e demais considerações sobre seu processo na realização dos desenhos.

Em análise às salas de Desenho, observou-se que, além das discussões nos fóruns, foram disponibilizados também o acesso a fotos, imagens e vídeos relacionados ao conteúdo estudado.

Em entrevista aos acadêmicos sobre o acesso à plataforma, os alunos responderam:

Sim, acessei e consegui sanar muitas dúvidas. A professora que o diga! (Aluno l);

Não acessava a plataforma com frequência porque não tinha acesso $a$ internet. (Aluno II);

Sim. Sempre fui muito participativa, eu acho que a plataforma é uma maneira de você estudar e se preparar para as provas. (Aluna III);

Acessava pouco, pois estava mais preocupado com as atividades. Retornei à sala depois para tirar dúvidas. (Aluno IV);

Sim, na medida do possível. (Aluna V);

No início do curso me dedicava mais, agora entrava sempre, mas lia os comentários e saia, não postava mais minhas respostas, por achar que ficava repetindo as mesmas respostas. (Aluna $\mathrm{VI}$ ).

De acordo com as falas acima é possível afirmar que os alunos que acessaram a plataforma responderam afirmativamente sobre conseguir sanar as dúvidas que surgiam durante e depois dos estudos da disciplina.

Sobre existir ou não uma evolução em seus desenhos, responderam deste modo:

Houve [...] uma evolução muito grande. Só não é maior por falta de tempo para praticar. (Aluno I);

Sim. (Aluno II);

Nossa! Sem comentários: eu não desenhava nada, eu só esboçava. Para quem tinha dificuldade em desenhar uma árvore e consegue desenhar um Jhon 
Lennon, por exemplo, é uma evolução extraordinária! Eu aprendi a gostar de Desenho a partir do curso. (Aluno III);

Houve muita evolução! (Aluno IV);

Sim, com o conhecimento das técnicas usadas, eu melhorei bastante. (Aluno $\mathrm{V})$;

Acho que parei no tempo. Quando era mais nova tinha bastante facilidade em desenhar olhando, mas tive várias dificuldades em aceitar os não reconhecimentos, muitas pessoas viam, gostavam e nem mesmo agradeciam, por ter sido tão desvalorizado, não abro "brecha" para expandir de novo [...] (Aluna VI).

Evoluir nos desenhos é uma importante base para a evolução artística do estudante das Artes Visuais, pois "dominando o desenho, a pessoa com pretensões artísticas modestas poderá desenvolver trabalhos expressivos" (HALLAWELL, 2010, p.10). Observa-se que a maioria dos acadêmicos confirmou haver evolução em seus desenhos, alguns até com certo entusiasmo, exceto a aluna VI, que relacionou sua estagnação a problemas exteriores ocorridos antes do curso, o que demonstra também um desafio para a EAD:

O primeiro grande desafio a ser enfrentado pelas instituições provedoras de educação aberta e a distância refere-se, portanto, mais a questões de ordem sócio-afetiva do que propriamente a conteúdos ou métodos de cursos; mais estratégias de contato e interação com os estudantes do que a sistemas de avaliação e de produção de materiais [...]. (BELLONI, 2006, p.45).

Mesmo reconhecendo a evolução nos desenhos, durante a entrevista os acadêmicos apontaram dificuldades encontradas durante os estudos da disciplina Desenho como consta nas falas a seguir:

Aula prática. Precisaria ter muito mais aula prática com acompanhamento do professor. Saber o que está fazendo errado ou o que deve ser melhorado. (Aluno I);

Minha dificuldade com a elipse', mas superei com a ajuda da professora. (Aluno II);

Acho que minha dificuldade foi a mesma que todos encontraram, que foi o tempo: deveria ter um tempo maior para o desenho. Deveria haver mais oficinas. (Aluno III);

Minha dificuldade foi com a anatomia humana. Desenhar o modelo vivo, pois eu desenhava muito modelos de revistas... (Aluno IV);

A maior dificuldade foi com o portfólio de figura humana: é muito difícil desenhar figura humana e principalmente com técnicas úmidas. (Aluno V); 
Acho que a maior dificuldade foi o tempo, entendo que muitos moram fora, mas acho que deveriam ter mais oficinas em outras datas, para podermos sanar mais as dúvidas. São muitos alunos e por mais que o professor tenta dedicar uma atenção diferenciada, acabamos ficando com alguma dúvida. (Aluno VI).

Para Belloni (2006), na educação a distância quem ensina é a instituição e essa deve proporcionar nos discentes a autonomia necessária à sua aprendizagem. No curso de Artes Visuais, portanto, ainda existem lacunas quanto à autonomia dos estudantes, sendo necessárias algumas adaptações e mudanças como o acesso a videoaulas ou a webconferência, estimulando-os a produzirem seus desenhos sem a presença física do professor. $E$ ao questionarmos os acadêmicos sobre o que seria necessário para a melhoria do aprendizado nos estudos de Desenho foram apontadas possíveis mudanças e adaptações:

Mais práticas no encontro presencial e mais aulas presenciais. (Aluno I);

Mudança na mentalidade dos alunos sobre a consciência de desenho, pois assim facilitaria a representação do desenho. (Aluno II);

Mais aulas presenciais de disciplinas práticas. (Aluno III);

O aluno cobrar de si mesmo e haver mais informações das técnicas de desenho. (Aluno IV);

[...] na minha opinião tinha que ter vídeo aula para melhorar o aprendizado. (Aluno V);

[...] acho que deveria ter mais oficinas práticas, a fim de sanar todas as dúvidas. (Aluno $\mathrm{VI}$ ).

Durante a graduação em Artes Visuais, é importante que o acadêmico vivencie a linguagem do desenho e se prepare para tornar-se professor, pois

o olhar do professor sobre o desenho é determinado pelas suas concepções do desenho que foi adquirido durante sua vida acadêmica e profissional. Esse conhecimento modela sua postura na sala e a forma que ele observa o desenho das crianças, sendo permeado pelo incentivo ou advertência, ou mesmo pela indiferença. (FORMIGA; COUTINHO, 2004, p.75).

Outro instrumento de auxílio utilizado no processo de ensino-aprendizagem das disciplinas da UAB/Unimontes é o material didático da disciplina, que para os alunos, teve grande importância para os estudos: 
O material didático foi importante. (Aluno I);

Sim. Muito importante. (Aluno II);

Eu comprei mais livros para aprofundar nos estudos do desenho, mas o material didático foi muito importante para meus estudos. (Aluno III);

[...] consultava muito o material didático. (Aluno IV);

Ajudou bastante. (Aluno V);

Apesar de usar outros materiais, como internet, filmes, revistas e livros, sem o material ficaríamos deslocados. (Aluno VI).

Disponibilizar o material didático e adequá-lo às especificidades do curso e da disciplina, auxiliando o estudante na produção dos seus desenhos, possibilitou promover a flexibilização de ensino de aprendizagem, pois, como citado pelos alunos, todos utilizaram o material para os estudos.

\section{A percepção da Professora}

Em relação às dificuldades encontradas, a professora comentou os desafios em acompanhar a realização dos exercícios pelos alunos, identificando seus traços e conhecendo suas limitações e potencialidades.

A dificuldade inicial foi a necessidade de compreensão do processo de ensino/aprendizagem a distância e a mediação da máquina (computador). Nesse sentido, tornou-se necessário criar estratégias a cada novo desafio, e principalmente refletir sobre o desenvolvimento da prática artística e dos conteúdos teóricos nessa modalidade. No trabalho com o desenho é fundamental que o professor acompanhe e avalie cada ação do ato de desenhar do aluno, conhecendo potencialidades, limitações e/ou dificuldades e a identidade do traço de cada um, e tal fato foi buscado com muita dificuldade devido às especificidades dos recursos tecnológicos disponíveis [...] (Professora B)

Para Belloni (2006), é fundamental prover os estudantes de meios que permitam relações pessoais, embora não contíguas e, para assegurar esta interação, é essencial o uso de mídias capazes de criar e de sustentar a comunicação pessoal, embora não presencial.

Durante análise dos portfólios dos acadêmicos observou-se que outra estratégia didática utilizada pela professora foi escrever bilhetes (FIG.1 e 2) e anexá-los ao lado dos desenhos dos alunos para que estes, ao 
receberem seus portfólios, ficassem cientes das orientações acerca de seus desenhos. É notável nos portfólios que junto às anotações do próprio aluno, haviam também dúvidas encontradas pelos mesmos durante a produção dos desenhos. As professoras escreviam bilhetes acerca dessas observações e dúvidas e os anexavam nos portfólios, dando assim um feedback referente às dúvidas suscitadas.

FIGURA 1 - Considerações do aluno sobre seus desenhos.

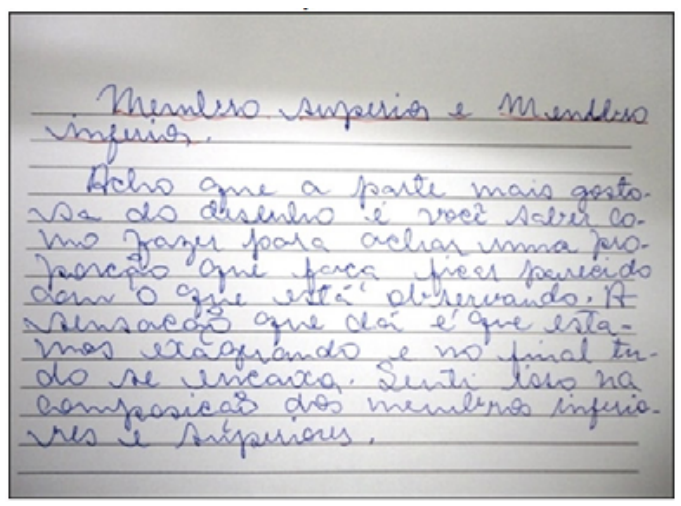

Fonte: portfólio Desenho III.

FIGURA 2 - Desenho do membro inferior com bilhete feedback anexo em destaque.

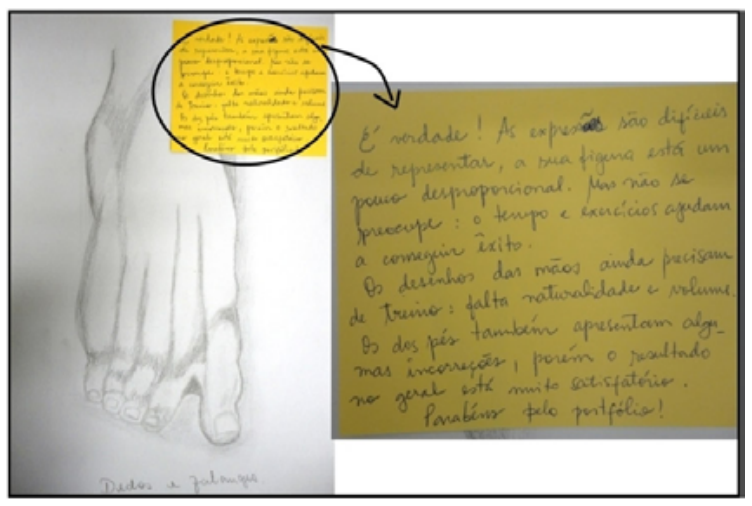

Fonte: portfólio Desenho III. 
Para Freire (2005), educação é comunicação e a comunicação realiza-se somente através de ações de diálogo, de troca e de encontro entre os sujeitos. Durante análise do processo de ensino-aprendizagem em Desenho, observamos que tentativas ocorreram como modo de compensar a falta de comunicação presencial entre professores e alunos utilizando o a plataforma Virtualmontes para o esclarecimento de dúvidas, postagens de orientações, de fotos e imagens, como também a disponibilização de links para acesso a sítios e vídeos.

Durante o desenvolvimento do curso, várias estratégias didáticas foram elaboradas e testadas, buscando uma melhor interação entre professor e aluno, sobretudo na avaliação das atividades práticas. Nesse sentido, o 'retorno' sobre os avanços e limitações relacionados à técnica, foram exaustivamente estudados. Em relação aos bilhetes feedbacks: os mesmos foram muito satisfatórios, porém acarretam muito tempo de elaboração pelo professor [...] É importante ressaltar ainda que, pelo volume de comentários, os bilhetes foram redigidos pelo professor formador e tutor à distância (Desenho l e II) e entregues ao fim do mesmo semestre, e nos outros momentos (Desenho III e IV), foram entregues durante o encontro presencial do semestre posterior. No segundo momento (Desenho IV), foi utilizado, como feedback, uma fala rápida, nos intervalos dos encontros presenciais da disciplina, para facilitar o entendimento, sobretudo das limitações e possibilidades expressivas de cada um, uma vez que se tratava da última experiência direta com o desenho no curso(Professora "B")

Diante da busca por estratégias para estabelecer uma melhor comunicação, percebe-se os desafios encontrados a cada estratégia, assim como suas possibilidades; "nas relações pedagógicas existe também o conflito, que não anula o diálogo, que é parte dele, e, por isso, é necessário que seja enfrentado e trabalhado" (GADOTTI, 1995, p.18).

Ao questionarmos a professora se a mesma considerava importante o encontro presencial:

Sim, mas no sentido de ser uma 'aula inaugural', e não'a aula'. Muitos alunos confundem o encontro presencial com a realização da disciplina, ficando muito ansiosos e criando falsas expectativas em relação ao encontro. É preciso sempre lembrá-los que a característica do curso é a distância, e o encontro presencial é apenas o início das atividades. Mas eu acho que neste momento ainda é preciso existir essas aulas. (Professora "B"). 
Sobre o progresso nos desenhos dos alunos

Depende do que se entende por progresso. A função do ensino do desenho na graduação licenciatura é a de proporcionar uma experiência estética e experimentação técnica do desenho e suas possibilidades expressivas, o que se difere do bacharelado, onde a finalidade técnica é mais presente. Considero progresso um aluno que parou de desenhar na primeira infância, e retorna agora, mais de 30 anos depois, e consegue sair do desenho esquemático para uma observação mais elaborada, com maior complexidade técnica. Ainda que todos os alunos não tenham se desenvolvido homogeneamente, acredito que cada um avançou, dentro seu próprio tempo. Mas se for seguir a ementa $100 \%$ a maioria não, mas $90 \%$ dos alunos que tinham dificuldade conseguiram avançar dentro das suas limitações, pois saíram daqueles desenhos esquemáticos - como árvores, casas já prontos, e conseguiram perceber a diferença no desenho de observação. (Professora "B").

Sobre as melhorias necessárias ao curso, houve considerações sobre a estrutura adequada para a realização das aulas presenciais e a distância e também em mudanças nas avaliações, pois para ela, no processo de ensino-aprendizagem, a avaliação deve estar de acordo com a especificidade da disciplina, e os exercícios práticos deveriam ser avaliados com maior nota que as avaliações teóricas:

Todas as melhorias são de ordem estrutural:

Atelier com pranchetas para desenvolver desenhos em formatos maiores (A3) e pia para trabalhos úmidos; Precisa haver um espaço.[...]; Desenvolvimento de recursos de imagem na plataforma, pois a plataforma moodle é mais de texto do que de imagem; melhor conexão com internet, recursos de acesso à visualização de imagens e vídeos; tinha que me policiar ao colocar as imagens, pois a internet dos polos era lenta e dificultava o acesso dos alunos às imagens disponibilizadas e se o nosso objeto de estudo é a imagem, fico limitada [...];. Acesso à webconferência, uma vez que os chats podem auxiliar apenas nas dúvidas teóricas e não nas práticas; [...]. Capacitação e/ou formação do tutor presencial: isso é importante porque nos momentos de dificuldade do aluno, quem está mais próximo é o tutor presencial. Utilização de videoaulas, como acontece na UAB da UFG e UFMG em que são disponibilizados recursos para montar vídeos. O vídeo ajuda demais, tanto que trabalhando com a disciplina Gravura - de material produzido pela UFG, só foi possível porque já havia os vídeos disponíveis para acesso. (Professora "B"). 
Em análise ao PPP do curso de Artes Visuais na modalidade a distância, são citadas as necessidades de uma sala própria para o desenvolvimento das aulas de atelier, como o Desenho, assim como a divisão da turma em grupos para as aulas. De acordo com a entrevista com a professora, tais considerações levantadas no PPP não foram efetivadas pelos Polos de Apoio Presencial para os estudos da disciplina. E, para uma maior evolução nos desenhos, caberia um valor maior às atividades práticas, estimulando à produção artística, visto que os valores atribuídos às avaliações de caráter teórico ainda predominam com nota maior em disciplinas de caráter prático. Outra possibilidade apontada seria a contratação de um tutor presencial com formação em Artes Visuais para auxiliar os alunos na execução das atividades práticas, ou mesmo uma capacitação dos tutores que não são graduados em Artes Visuais.

\section{CONSIDERAÇÕES FINAIS}

Este estudo possibilitou melhor compreender as propostas de Educação Aberta e a Distância (EAD) acerca da democratização do saber, independente do tempo e do espaço. Foi possível concluir que há a possibilidade de ocorrer o aprendizado na modalidade de ensino a distância em um curso que contempla atividades práticas como o curso de Artes Visuais. A cada etapa do processo disciplinar é comum entre docente e discentes lidar com as dificuldades, mas o mais importante é a busca por estratégias para a melhoria dos estudos.

Durante análise das salas de Desenho na plataforma Virtualmontes, pode-se observar que nas quatro disciplinas houve uma relação proposta entre o material didático, as discussões do fórum e os exercícios práticos de desenho solicitados aos alunos, de maneira que o acadêmico, à medida que prosseguia nos estudos da disciplina, poderia realizar os exercícios práticos e teóricos, garantindo o estudo do material didático, de modo que a prática e a teoria acerca dos estudos de desenho se complementassem. Possivelmente, o perfil da professora pesquisada com formação e experiência no ensino e também na educação a distância tenham contribuído para alcançar bons resultados ao fim dos estudos do Desenho 
Visando alcançar maiores melhorias no desenvolvimento da disciplina Desenho no curso de Artes Visuais UAB/Unimontes, poderiam ocorrer mudanças que ainda não aconteceram e que provavelmente diminuiriam as dificuldades encontradas, como proporcionar aos acadêmicos a visualização de atividades para melhor compreensão nos estudos através do AVA com a disponibilização de videoaulas gravadas para a disciplina ou mesmo a webconferência. Tais alternativas seriam importantes para a contribuição nas melhorais no processo de ensino-aprendizagem do desenho, contribuindo com a formação autônoma necessária ao perfil de um estudante em EAD.

\section{VISUAL ARTS AND DISTANCE EDUCATION: A POSSIBLE LEARNING?}

ABSTRACT: The objective of this work is to present the data of the research developed during the specialization course of didactic and methodology at the State University of Montes Claros (Unimontes). This research has the objective to grasp the teachinglearning process in a distance-learning Design discipline in a graduate course of Visual Arts, identifying the difficulties encountered by the teachers and students, as well as the didactic strategies used. The collection of data was done by interview, documental research with portfolios of design and analysis of the virtual rooms. The conclusion is that it is possible to learn Design in a distance-learning course if there is a good infrastructure at the institution and that it provides the necessities of this discipline.

KEYwords: Distance Education. Visual Arts. Teaching- learning. Design.

\section{ARTES VISUALES Y EDUCACIÓN A DISTANCIA: ¿UN APRENDIZAJE POSIBLE?}

RESUMEN: Este trabajo tiene como objetivo presentar los datos de una investigación realizada durante el curso de especialización en Didáctica y Metodología de la Educación Superior en la Universidad Estatal de Montes Claros (Unimontes); así como comprender el proceso de enseñanza-aprendizaje de la asignatura de Disenõ en una licenciatura en Artes Visuales a distancia, identificando las dificultades encontradas por el profesor y los alumnos, bien como las estrategias de enseñanza utilizadas. La recogida de datos se realizó mediante entrevista y investigación documental con carteras de Diseño y análisis de las salas virtuales. La conclusión es que es posible aprender el diseño en un curso a distancia si existe una buena estructura en la institución que atienda a las necesidades de esta asignatura.

Palabras clave: Educación a Distancia. Artes visuales. Enseñanza-aprendizaje. Diseño. 


\section{NOTAS}

1) Elipse: forma circular ovalada utilizada para representar parte de um objeto representado tridimensionalmente. Exemplo: desenho da boca de uma garrafa visualizada lateralmente.

\section{REFERÊNCIAS}

BELLONI, M. L. Educação a Distância. 4. ed. Campinas: Autores Associados, 2006.

CADERNO DE DIRETRIZES. Montes Claros: Universidade Aberta do Brasil/Unimontes, 2008.

COUTINHO, R. Formação do professor de Artes. In: BARBOSA, A. M. (Org.). Inquietações e mudanças no Ensino da Arte. 2. ed. São Paulo: Cortez, 2003. p. 153-159.

DIAS, C. C. M. Um olhar sobre a abordagem metodológica do curso online de iniciação à leitura em inglês do Projeto Unimontes Virtual. Universidade Estadual de Montes Claros - Unimontes, 2005.

FORMIGA, B. G.; COUTINHO, S. G. Nem tudo que teclas é computador: uma análise do processo de desenho de professores primárias. In: MEDEIROS, M. B. de (Org.). Arte em Pesquisa: especificidades. Brasília: Editora da Pós-graduação em Arte da Universidade de Brasília, 2004.

FREIRE, P. Pedagogia do Oprimido. 45 ed. Rio de Janeiro: Paz e Terra, 2005.

GADOTTI, M. Pedagogia da práxis. São Paulo: Cortez, 1995.

GIL, A. C. Como elaborar projetos de pesquisa. São Paulo: Atlas: 2002.

HALLAWELL, P. À mão livre e as técnicas do desenho. São Paulo: Editora Melhoramentos, 2010.

PROJETO POLÍTICO PEDAGÓGICO. Curso Artes Visuais Licenciatura - UAB, Montes Claros, 2008.

SCHAFF, A. História e verdade. São Paulo: 1987.

VIEIRA, F. M. S. Ciberespaço e educação: possibilidades e limites da interação dialógica nos cursos online Unimontes Virtual. Dissertação [Mestrado em Tecnologias na educação] Programa de Pós-Graduação em Educação, Universidade de Brasília - UnB. Brasília, 2003.

ANDRY MÁRCIA LOPES: Graduada em Artes pela Universidade Estadual de Montes Claros (Unimontes). Especialista em Didática e Metodologia do Ensino Superior pela mesma Universidade. Atualmente 
é Professora do Instituto Federal de Educação, Ciência e Tecnologia do Norte de Minas Gerais. Tem experiência na área de Artes, com ênfase em Artes Plásticas.

E-mail: andryllopes@yahoo.com.br

FÁBIA MAGALI SANTOS VIEIRA: Doutora em Educação pela Faculdade de Educação da Universidade de Braślia (UnB). Professora e pesquisadora da Universidade Estadual de Montes Claros (Unimontes). E-mail: fabiamsv@gmail.com 
